\title{
A Study on the development therapeutic environmental rating scales for the elderly people with dementia in nursing homes
}

\author{
- Focused on the TESS-NH environmental rating scale Analysis \\ 치매성 고령자를 위한 노인요양시설의 치료적 환경평가척도 개발에 관한 연구 \\ - TESS-NH 환경평가척도 분석을 중심으로
}

Lee, Young chang* 이영창

\begin{abstract}
Purpose: AIn recent years, the rapid progress of aging and the increase in the elderly people with dementia is becoming a big social issue. Therefore, this paper studies the development of therapeutic environmental rating scales for the elderly people with dementia in korean nursing homes. Methods: We identify the development process and structure of TESS-NH and understand the details of its nature and features. Then, based on the detailed items, we provide major scale factors which do influence on therapeutic environmental rating scales using PCA. Results: In the results, TESS, in the case of the initial stage of TESS-NH, has an advantage to evaluate on physical environments for a short period of time. TESS-2 + sets a large rage of activities of the elderly people with dementia, and tries to evaluate ongoing cares. TESS-NH has a complete set of well-thought-out assessment features for improving quality of care (Quality of Care) On the other hand, the main factors affecting the therapeutic environmental rating scales in nursing homes are "a consideration for facility management (Care for facilities' maintenance)", "a consideration for spatial cognition (Care for spatial cognition) ", and "a consideration for the safety (Care for safety)". Implications: In the future, to develop the therapeutic environmental rating scales on Korea's dementia nursing home, we should actively consider cares of spaces and facility utilization which the residents (the elderly people with dementia) are more secure and comfortable.
\end{abstract}

Keywords Dementia Elderly, Nursing Home, TESS-NH, Environmental rating scale

주 제 어 치매성 고령자, 노인요양시설, TESS-NH, 환경평가척도

\section{Introduction}

\subsection{Background and Objective}

우리나라는 2000년 초반에 들어서부터 고령화의 급속한 진행과 함께 장1)기적 간병이 수발되는 노인요양시설에 대한 케어환경의 문제가 중요한 사회적 이슈가 되고 있다. 무엇보 다 심각한 것은 급속하게 증가되고 있는 치매성 고령자의 증

\footnotetext{
* Member, Adjunct Professor, PhD,

Division of Environmental Science and Ecological Engineering, Korea University (envi0320@gmail.com)
}

가로서 "노인인구 $14.7 \%$ 가 의심되며, $7.6 \%$ 는 이미 치매로 판 정되었다."라는 사실이다.1)

한편, 정부는 1981 년 노인복지법을 제정하고, 노인복지시 설의 세분화 이후, 1997년부터 치매관리, 노인재활요양사업 의 실시, 2007년 노인장기요양보험 법안의 통과로 인해 노인 요양의 정책적 분야에서는 일정 전환기를 맞이하게 되었고,2)

1) 이연숙, 임수현, 황지혜, 치매노인환경을 위한 선도적 디자인 지 침의 체계 비교 분석, 대한건축학회논문집 계획계, 27권11호, 2011, pp91

2) 변혜령, 정미렴, 노인요양시설에 관한 국내연구 분석-1990년 이 후 학위논문과 학술지 게재논문을 대상으로-, 한국주거학회, 19 권2호, 2008, pp93 
고령자보건복지시설분야, 특히 급속히 증가하는 치매성 고령 자 요양시설환경에 있어서, 기존의 그룹케어로부터 개별적 케 어를 위한 개인병실의 제공 변화, 가정적 분위기 등의 생활환 경을 요양시설에 적용하는 등, 치료환경에 도움을 주기 위한 시설환경의 변화 조짐을 볼 수 있다.

그러나 이러한 시설에 있어서 보다 좋은 치매케어가 제공 되기 위해서는 제 3 자의 중립자적 입장에서의 평가제를 통한 치매노인에게 직.간접적으로 영향을 미치는 물리적 특색과 이 와 관련한 생활환경이 포함된 케어환경평가수단의 구축이 선 행되어야 할 것이다.

본 연구에서는, 우리나라의 노인요양시설에 적용가능한 치 매성 고령자를 위한 치료적 환경평가척도를 개발하기 위한 가능성 검토의 일환으로, 물리적 특색을 단기간에 관찰하기 위해 만든 평가척도로서 미국에서 개발된 Therapeutic environment Screening Survey for Nursing Homes (TESS-NH)을 중심으로, 이것의 개발과정 및 구조를 파악함으 로 주요 항목들의 분류화 작업을 통해 보다 세부적인 성격과 특색을 살펴본다.

다음으로, 앞에서의 평가항목들을 기초로 하여, 치료적 환 경평가척도에 대해서 어떠한 주요척도 요인이 영향을 주고 있는가를 밝혀봄으로, 향후 우리나라의 치매성 노인요양시설 에 대해서 적용가능한 치매성 관련의 치료적 차원의 환경평 가척도를 개발되는데 참고적 자료로 활용되는 것을 목적으로 한다.

\subsection{Methods of Research}

본 연구방법에는, 먼저 치유환경평가지침(TESS, TESS-2+, TESS-NH)에 대한 개발 과정과 구조를 파악하고, 이 지침들의 내용들을 토대로 주요항목들의 세부적인 성격과 특색을 알아 보기 위하여 주요 항목들 간의 분류화를 실시하였다.

다음으로, TESS-NH에서 분류된 총12개 Protocols을 설문 항목으로 하여 Principal Component Analysis(PCA) 분석을 통해 치료적 환경평가에 대해 영향을 주는 평가척도의 주요 인을 밝혀 보았다.

이때, 실험평가에서 사용하는 요양시설내부이미지는 2008 년에서 2011년 사이에 개설된 5개 시설(구립서초노인요양센 터, 구립송파노인요양센터, 구립양천노인요양센터, 하남전문 요양원)에 대하여 인터넷조사 및 제한적 현장조사를 통해 확 보하였으며, 이것을 실험평가 대상자들에게 무기명 무작위방 식으로 이미지를 제시하였다.

실험평가 대상자는 고령자관련 요양시설 및 기타 건축시설 에 대하여 계획 및 설계를 경험한 관련 건축실무자 총 50 명을 대상으로 하였다. 이들의 주된 특성을 보면, 총 50 명 $(\mathrm{n}=50)$ 가 운데 요양시설과 관련하여 설계경험자는 22 명 $(\mathrm{n}=22)$, 미경험 자는 28 명 $(n=28)$ 인 반면, 구상단계 또는 기본계획까지 참여
한 경험자는 39 명 $(\mathrm{n}=39)$ 의 높은 경험도를 보이고 있었다. 또 한 요양시설에 대한 전문적인 건축적 지식의 욕구를 대부분 가지고 있다는 것이다.

이러한 평가대상자를 대상으로 5점 리커드척도(5-Point Likert type scale)를 이용한 앙케트조사에 의해 평가를 실시 하였으며, 조사기간은 2014년 4월부터 7월16일에 걸쳐 실시 하였다.

\section{TESS-NH}

\subsection{TESS-NH의 개발과정}

TESS-NH는 장기요양시설의 물리적 환경에 대하여 계통적 데이터를 수집하는 경우의 관찰수법으로서 미국에서 개발된 것으로 알츠하이머 증상(Alzheimer's disease) 및 그 밖의 치 매증 환자들에 대한 중요한 특성을 측정하기 위한 80 가지 이 상의 세부항목이 포함되어 있다.3)

이것들의 항목은 개개인의 환경적 조건의 특성을 조사하기 위하여 설계된 것으로 Philip Sloane박사의 지도와 C. Madeline Mitchell의 관리를 통해 진행되었던 연구프로젝트 팀이 약 10년간에 걸쳐서 발전시켰던 결과이다.

또한, TESS-NH의 일부는 국립노년학연구소, 퇴직연구재단 등의 연구조성금에 의하여 진행되었으며 관찰조사로서 상당 한 발전된 것은 알츠하이머 증상(Alzheimer's disease)대상의 특별케어유닛(SCU)에 대해서의 국립노년학연구소와의 공동 연구이다.

한편, TESS-NH는4) TESS 및 TESS-2+를 한층 더욱 내용적 으로 개정시킨 결과로서 초기단계의 TESS는, 알츠하이머 증 상(Alzheimer's disease)대상의 특별케어유닛(SCU)를 단시간 내 관찰하는 목적으로 1980년 말경에 개발되었다.

물리적 환경에 초점을 맞추고 있으며, (1)바닥표면의 청결 및 미끄러움, (2)번쩍거리는 빛은 없는가, (3)큰소리와 잡음은 없는가, (4)청소세제 냄새가 가득하지 않는가, (5)배설물의 냄 새가 가득하지 않는가, (6)거실에 사유물의 소지가 인정되고 있는가, (ㄱ)가정적 분위기의 공유 스페이스가 있는가, 8옥외 를 향한 액세스 정도, (9)소그룹을 위한 공간이 확보되어 있는 가, (10TV가 장시간 켜져 있는 상태이지 않는가, (11)조명은 적 당한가, (12)병실 내의 부억은 이용가능한가, 의 12 개 평가항목 으로 되어 있는 관찰수법이다. 이 수법은 각각 0 2점의 Range로 득점화하며 합계는 0 24점이 된다.

3）大原一興、オーヴェ・オールンド、痴呆性高齢者の住まいのか たち一南スウェーデンのグルプリビングー、彰国社、2000.

4) Sloane, P.D. \& Mathew, L. J. (eds.): Dementia units in long-term care, Jhon Hopkins University Press, 1991 
TESS-2+는5), 국립노년학연구소와 SCU에 있어서의 공통견 해를 도출하기 위해서 1990년 초경에 공동 개발되었다. 이것 은 Table 1과 같이, (1)일반적 디자인, (2)유지·관리, (3)공간·앉 는 장소, (4)조명, (5)잡음, (6)거실, (7)프라이버시와 개인화, (8) 방향감각을 위한 프로그램의 8관점 37 개 평가항목으로 되어 있다.

[Table 1] TESS-2+

\begin{tabular}{|c|c|}
\hline Protocols & Items(Summary) \\
\hline \multirow{3}{*}{ 1. General design } & $\begin{array}{l}\text { Relation between units and a nursing } \\
\text { station }\end{array}$ \\
\hline & $\begin{array}{l}\text { Exits to limit the residents' ability to } \\
\text { physically leave the unit }\end{array}$ \\
\hline & Floor design in 6 areas \\
\hline \multirow{3}{*}{ 2. Maintenance } & $\begin{array}{l}\text { Floor surfaces to be slippery and } \\
\text { uneven }\end{array}$ \\
\hline & Odors of cleaning detergent \\
\hline & $\begin{array}{l}\text { Number of handrails in } 5 \text { areas : } \\
\text { shared social spaces, halls, residents' } \\
\text { rooms, residents' bathrooms and so on. }\end{array}$ \\
\hline \multirow{4}{*}{ 3. Activity areas } & $\begin{array}{l}\text { Seating capacity in activity rooms and } \\
\text { dining rooms }\end{array}$ \\
\hline & $\begin{array}{l}\text { Public areas with a homelike } \\
\text { atmosphere }\end{array}$ \\
\hline & $\begin{array}{l}\text { Kitchen located on the unit available for } \\
\text { activities and resident and/or family use }\end{array}$ \\
\hline & Walkways in 9 outdoors \\
\hline \multirow[b]{2}{*}{ 4. Lighting } & Shinny surfaces \\
\hline & $\begin{array}{l}\text { Light levels in three areas of the unit: } \\
\text { hallways, activity areas, and resident } \\
\text { rooms }\end{array}$ \\
\hline \multirow[t]{2}{*}{ 5. Noises } & $\begin{array}{l}\text { Screaming or calling out and other } \\
\text { machines' noises }\end{array}$ \\
\hline & TV noises in 3 public areas \\
\hline \multirow{2}{*}{$\begin{array}{l}\text { 6. Residents' } \\
\text { rooms }\end{array}$} & Cue for resident rooms \\
\hline & Cue for resident bathrooms in 3 areas \\
\hline \multirow{3}{*}{$\begin{array}{l}\text { 7. Privacy and } \\
\text { personalization }\end{array}$} & $\begin{array}{l}\text { Privacy accomodations in resident } \\
\text { rooms }\end{array}$ \\
\hline & $\begin{array}{l}\text { Personal pictures and/or momentos in } \\
\text { Residents' Rooms }\end{array}$ \\
\hline & $\begin{array}{l}\text { Availability of personal furnitures in } 4 \\
\text { areas }\end{array}$ \\
\hline \multirow{2}{*}{$\begin{array}{l}\text { 8. Program for } \\
\text { social } \\
\text { interaction }\end{array}$} & $\begin{array}{l}\text { Visual stimulation provided throughout } \\
\text { the unit }\end{array}$ \\
\hline & Resident appearance in 3 public areas \\
\hline $\begin{array}{l}\text { Etc(Overall } \\
\text { environment) }\end{array}$ & $\begin{array}{l}\text { Overall atmosphere, residents' } \\
\text { participation in a program, and so on }\end{array}$ \\
\hline
\end{tabular}

또한, 평가척도로서 타당성에 있어서는 TESS의 경우, (Slone 외, 1991)6)의 연구에 의해서 SCU와 비SCU 간의 통계

5) The University of North Carolina at Chapel Hill, Program on Aging Disablement and Long-Term Care (www.unc.edu/depts/tessnh/tess_info.)
적인 유의적 차가 있다는 것이 검증 되어져 있다. TESS-2+에 있어서도, 연속된 조사결과 등에 의하여 실증적인 타당성이 밝혀져 있다.

\subsection{TESS- $\mathrm{NH}$ 의 구조파악}

TESS-NH의 이론적 기초는 국립노년학연구소와의 SCU에 대해서 공통견해를 형성했던 환경평가위원회에 의해서 1990 1992년경에 개발되었다. 위원회에서는 치매를 가지고 있는 사람들을 케어하는 경우의 물리적 환경에 있어서 여섯 가지의 주된 치료목표를 결정하고, 이것들을 다시 13 개의 관 점으로 전개하였다7).

그래서 최종적인 TESS-NH의 구조는 Table 2와 같이, 네 가 지의 치료목표 (1)안전·안심·건강, (2)방향감각, (3)프라이버시. 관리·독립성, (4)사회환경과, 12 개의 관점, (1)출입구 관리, (2)유 지관리, (3)청결도, (4)안전, (5)방향감각·사인, (6)프라이버시, (7) 병실의 독립성, (8)옥외를 향한 액세스, (9)조명, (10)잡음, (11)시 각·촉각의 자극, (12)공간·앉는 장소, 이상 32항목(종합평가를 포함)으로 분류되어진다.

\section{[Table 2] TESS-NH}

\begin{tabular}{|c|c|c|}
\hline $\begin{array}{c}\text { Purpose of } \\
\text { care }\end{array}$ & Protocols & Items \\
\hline \multirow{14}{*}{$\begin{array}{c}\text { Safety·Secure } \\
\text { Health }\end{array}$} & \multirow{3}{*}{ Exit Control } & Exit disguise from residents \\
\hline & & $\begin{array}{l}\text { Number of elevators off of the } \\
\text { unit, Number of exits off of } \\
\text { the units }\end{array}$ \\
\hline & & Alarms \\
\hline & \multirow{4}{*}{ Maintenance } & Shared social spaces \\
\hline & & Halls \\
\hline & & Residents' rooms \\
\hline & & Residents' bathrooms \\
\hline & \multirow{5}{*}{ Cleanliness } & Shared social spaces \\
\hline & & Halls \\
\hline & & Residents' rooms \\
\hline & & Residents' bathrooms \\
\hline & & $\begin{array}{l}\text { Unpleasant odors in both } \\
\text { public areas and residents' } \\
\text { rooms }\end{array}$ \\
\hline & \multirow{2}{*}{ Safety } & $\begin{array}{l}\text { Floor surface which are slippery } \\
\text { and whose materials are } \\
\text { changed }\end{array}$ \\
\hline & & $\begin{array}{l}\text { Handrails to assist residents in } \\
\text { moving through the unit, and } \\
\text { to aid in rising from the toilet }\end{array}$ \\
\hline
\end{tabular}

6) Sloane, P.D. \& Mathew, L. J. (eds.): Dementia units in long-term care, Jhon Hopkins University Press, 1991

7) The University of North Carolina at Chapel Hill, Program on Aging Disablement and Long-Term Care (www.unc.edu/depts/tessnh/tess_info.) 


\begin{tabular}{|c|c|c|}
\hline $\begin{array}{l}\text { Purpose of } \\
\text { care }\end{array}$ & Protocols & Items \\
\hline \multirow{3}{*}{ Orientation } & \multirow{3}{*}{$\begin{array}{l}\text { Orientation. } \\
\text { cueing }\end{array}$} & Cue for resident rooms \\
\hline & & Cue for resident bathrooms \\
\hline & & Cue for activity areas \\
\hline \multirow{18}{*}{$\begin{array}{c}\text { Privacy.Mainte } \\
\text { nance- } \\
\text { Autonomy }\end{array}$} & Privacy & $\begin{array}{l}\text { Privacy in resident rooms with } \\
\text { a privacy curtain, solid } \\
\text { partition, and a movable wall } \\
\text { barrier }\end{array}$ \\
\hline & \multirow{6}{*}{$\begin{array}{l}\text { Unit } \\
\text { autonomy }\end{array}$} & $\begin{array}{l}\text { Relation between units and a } \\
\text { nursing station }\end{array}$ \\
\hline & & Provision for staff paperwork \\
\hline & & Unit serves as pathway \\
\hline & & $\begin{array}{l}\text { Ability to provide eating } \\
\text { services to residents on the unit }\end{array}$ \\
\hline & & $\begin{array}{l}\text { Ability to provide bathing } \\
\text { services to residents on the } \\
\text { unit }\end{array}$ \\
\hline & & $\begin{array}{l}\text { Ability to provide formal } \\
\text { activity services to residents on } \\
\text { the unit }\end{array}$ \\
\hline & \multirow{3}{*}{$\begin{array}{l}\text { Access to } \\
\text { outdoors }\end{array}$} & $\begin{array}{l}\text { Courtyard accessibility of an } \\
\text { outdoor space to the residents }\end{array}$ \\
\hline & & $\begin{array}{l}\text { Courtyard appearance : warm } \\
\text { materials including wood and } \\
\text { brick, comfortable seating, } \\
\text { varied plantings, shade, a } \\
\text { barrier that is visually } \\
\text { appealing, bird feeders } \\
\end{array}$ \\
\hline & & $\begin{array}{l}\text { Courtyard functionality : seating } \\
\text { available, walking paths, space } \\
\text { for gardening, safe barrier }\end{array}$ \\
\hline & \multirow{3}{*}{ Lighting } & $\begin{array}{l}\text { Light intensity for the older } \\
\text { person who needs almost } \\
\text { three times as much light as a } \\
20 \text { year old }\end{array}$ \\
\hline & & $\begin{array}{l}\text { Glare which is usually a } \\
\text { combination of light sources } \\
\text { and floor surface }\end{array}$ \\
\hline & & $\begin{array}{l}\text { Even lighting throughout the } \\
\text { room }\end{array}$ \\
\hline & \multirow{5}{*}{$\begin{array}{l}\text { Visual-tactile } \\
\text { stimulation }\end{array}$} & TV noises in public areas \\
\hline & & $\begin{array}{l}\text { Residents' screaming or calling } \\
\text { out, staffs' creaming or calling } \\
\text { out, and other machines' noises }\end{array}$ \\
\hline & & $\begin{array}{l}\text { View of courtyard from } \\
\text { bedrooms and public areas }\end{array}$ \\
\hline & & $\begin{array}{l}\text { Tactile stimulation which are in } \\
\text { several program areas and in } \\
\text { hallways }\end{array}$ \\
\hline & & $\begin{array}{l}\text { Visual stimulation which are in } \\
\text { several program areas and in } \\
\text { hallways }\end{array}$ \\
\hline \multirow[b]{2}{*}{$\begin{array}{l}\text { Social } \\
\text { interaction }\end{array}$} & \multirow[b]{2}{*}{ Activity areas } & Chairs in resident rooms \\
\hline & & $\begin{array}{l}\text { Unit spaces : multi-purpose } \\
\text { room, activity room, dining } \\
\text { room, lounge, alcove, and } \\
\text { others }\end{array}$ \\
\hline
\end{tabular}

\begin{tabular}{|c|c|c|}
\hline $\begin{array}{l}\text { Purpose of } \\
\text { care }\end{array}$ & Protocols & Items \\
\hline & & $\begin{array}{l}\text { A path which the resident can } \\
\text { follow }\end{array}$ \\
\hline & & $\begin{array}{l}\text { Places to sit and rest while } \\
\text { wandering }\end{array}$ \\
\hline & & $\begin{array}{l}\text { Configuration of rooms, } \\
\text { allowing easy visual access to } \\
\text { public areas are probably } \\
\text { easier for residents }\end{array}$ \\
\hline & & $\begin{array}{l}\text { Homelike atmosphere through } \\
\text { the use of non-institutional } \\
\text { finishes and furnishings: } \\
\text { curtains, wallpaper, variety of } \\
\text { furniture with texture, carpet or } \\
\text { hard wood floors, lamps, } \\
\text { wall-hangings, bookshelves, etc }\end{array}$ \\
\hline & & $\begin{array}{l}\text { Kitchen availability with sink, } \\
\text { cooking appliance, refrigerator, } \\
\text { and counter space }\end{array}$ \\
\hline & & $\begin{array}{l}\text { Personalizing residents' rooms } \\
\text { which have three personal } \\
\text { pictures and/or momentos }\end{array}$ \\
\hline & & $\begin{array}{l}\text { Non-institutional furniture such } \\
\text { as bed, bureau or dresser, } \\
\text { wardrobe, table or chair. }\end{array}$ \\
\hline & & $\begin{array}{l}\text { Resident appearance which is } \\
\text { well-groomed }\end{array}$ \\
\hline Etc & $\begin{array}{c}\text { Overall } \\
\text { physical } \\
\text { environment }\end{array}$ & $\begin{array}{l}\text { On a scale of } 1 \text { to } 10 \text {, global } \\
\text { assessment of the physical } \\
\text { environment of } \\
\text { the unit }\end{array}$ \\
\hline
\end{tabular}

\section{3. 치매성 노인요양시설에 대한 치료적 환경평가에 영향을 주는 평가척도의 주요인}

\section{1 분석결과}

[Table 3]과 같이, 분석을 위한 설문지 구성에 있어서, 앞장 에서 파악된 TESS-NH 4개의 속성(Attributes), "안전·안심·건 강(Safety·Secure-Healthy)", "방향성(Orientation)", "프라이버 시·관리·독립성(Privacy·Maintenance-Autonomy)", "사회환경 (Social interaction)"에 귀속되는 총 12 개의 프로트콜 (Protocols)을 설문항목(Contents)으로 선정하였다. 그리고 5 점 리커드척도(5-Point Likert type scale)를 통해 노인요양시 설에 있어서 치료적 환경평가에 어느 정도 영향을 줄 수 있는 가에 대하여 평가를 받았다.

다음으로, [Table 4]와 같이 주성분분석(PCA)에 있어서는, Table 3의 설문지 구성에서 예시하였던 설문항목(Contents), 총 12 개 항목을 다시 설명변수로 설정하여 분석을 진행하였 고 주요인(PC)으로 추출된 3개의 Factor는, 앞서 진행한 설문 지 평가 결과 데이터로부터 유도되었다. 
분석 결과, 3 개의 multi-item factors들은 1.0 보다 큰 고유 값(eigenvalue)을 유지하고 있었으며, 아이템 로딩 계수 (loading coefficients of the items)가 0.50 이상이었고, 전체 분산(overall variance was explained )의 $70 \%$ 가 3 개의 factor 에 의해서 설명되었다.

또한 3개의 주요인 Factor는, "시설 관리에 대한 배려(Care for facilities' maintenance)", "공간인지에 대한 배려(Care for spatial cognition)", "안전을 위한 배려(Care for safety)" 라는 요인 명으로 정의 할 수 있었다.

그리고 3개의 주요인 factor에 대하여 Cronbach's alpha를 사용하여 내적 신뢰성(internal reliability)에 대한 테스트 한 결과, "시설 관리에 대한 배려(Care for facilities' maintenance)", "공간인지에 대한 배려(Care for spatial cognition)"는 상당히 신뢰할 수 있는(0.80 or higher) 내적 신 뢰성을 보여주었다. 그러나 안전을 위한 배려(Care for safety)"에 대해서는 내적 신뢰성이 다소 낮은(0.37) 결과가 나 왔다.

[Table 3] Survey instrument

\begin{tabular}{|c|c|}
\hline Attributes & Contents \\
\hline \multirow{4}{*}{$\begin{array}{l}\text { Safety·Secure. } \\
\text { Healthy }\end{array}$} & Exit control \\
\hline & Maintenance \\
\hline & Cleanliness \\
\hline & Safety \\
\hline Orientation & Orientation-cueing \\
\hline \multirow{6}{*}{$\begin{array}{l}\text { Privacy·Maintenance. } \\
\text { Autonomy }\end{array}$} & Privacy \\
\hline & Unit autonomy \\
\hline & Access to outdoors \\
\hline & Lighting \\
\hline & Noises \\
\hline & Visual-tactile simulation \\
\hline Social interaction & Activity areas \\
\hline
\end{tabular}

[Table 4] Principal components analysis of Factors $(n=50)$

\begin{tabular}{|c|c|c|c|c|}
\hline $\begin{array}{l}\text { Factors(italic) and } \\
\text { items (indented) }\end{array}$ & Mean & S.D. & $\begin{array}{c}\text { Cronbach's } \\
\text { alpha }\end{array}$ & $\begin{array}{l}\text { Eigen } \\
\text { value }\end{array}$ \\
\hline $\begin{array}{l}\text { Care for facilities' } \\
\text { maintenance }\end{array}$ & $2.97^{\mathrm{a}}$ & 1.22 & 0.88 & 4.75 \\
\hline Noises & 2.88 & 1.19 & - & - \\
\hline Lighting & 2.84 & 1.26 & - & - \\
\hline Visual-tactile simulation & 2.86 & 1.21 & - & - \\
\hline $\begin{array}{l}\text { Care for spatial } \\
\text { cognition }\end{array}$ & 3.14 & 0.97 & 0.84 & 2.93 \\
\hline Access to outdoors & 2.98 & 0.89 & - & - \\
\hline Orientation-cueing & 3.20 & 0.90 & - & - \\
\hline Care for safety & 3.08 & 1.12 & 0.37 & 1.66 \\
\hline Exit control & 2.78 & 1.04 & - & - \\
\hline Maintenance & 2.74 & 0.97 & - & - \\
\hline
\end{tabular}

aScale where " 1 " equals "very disagree" to " 5 " equals "very agree"
다음으로, 치매성 노인요양시설의 치료적 환경평가에 대해 서 어떠한 척도의 주요인이 영향을 주고 있는가를 의미하는 3 개의 주요인 factor에 대한 각각의 요인을 구성하는 아이템 을 통해 분석한 결과이다.

먼저, 시설 관리에 대한 배려(Care for facilities' maintenance)의 경우, "잡음", "빛", "시각.촉각·자극"이라고 하는 주 요 아이템들이 영향요인으로 작용하고 있었다. 요양시설에 대 한 시설 관리적 미흡으로 인하여 발생될 수 있는 과도한 잡음, 적절량 이상의 빛, 과도한 물리적 또는 정신적으로 장애를 줄 수 있는 시각.촉각.자극에 대한 배려가 우선적으로 평가 되어 야 한다는 환경평가척도의 중요도에 대한 인식을 알 수 있다. 다음으로, 공간인지에 대한 배려(Care for spatial cognition) 의 경우는 "야외로의 접근성", "방향-신호"의 주요 아이템이 영향요인으로 작용하고 있었다. 치매요양시설의 경우, 치매노 인은 방향감각, 공간인지에 대한 능력이 떨어짐으로 병실 혹 은 다른 장소에서 이동하거나 혹은 접근하는 경우, 방향과 신 호에 대한 배려가 환경평가척도에서 중요하다는 인식을 알 수 있다.

마지막으로 안전을 위한 배려(Care for safety)의 경우, "출 입구 통제", "유지 및 관리"라는 주요 아이템이 영향요인으로 작용하고 있었다. 치매노인의 경우, 보호자나 케어기버·관리 자가 동행하지 않거나 관리가 소흘해지는 경우에는 매우 중 대한 안전상의 문제가 발생함으로 환경평가척도에서 중요한 척도의 요인으로 인식되고 있다는 것을 알 수 있었다.

\section{Conclusion}

본 연구는 최근 고령인구의 증가와 함께 치매성 고령자의 증가로 인한 치매성 노인요양시설에 대한 치료적 환경평가척 도 개발의 필요성에 따라 향후 우리나라의 독자적인 환경평 가척도 개발의 참고적 자료를 제공하고자 진행하였다. 본 연 구의 결론은 다음과 같다.

1) TESS-NH의 초기단계였던 TESS의 경우, 알츠하이머 증 상(Alzheimer's disease)대상에게 초점을 맞추었으며, 입주자 들의 시설 사용 환경에 있어서 구체적으로 문제가 될 수 있 는 경우 또는 돌발적 상황에 의한 안전상에 문제가 바로 생 길 수 있는 경우를 염두에 두어 책정한 항목들의 특성을 알 수 있었다.

따라서 단시간 내에 입주자의 물리적 환경평가가 가능한 장점은 있었으나, 프라이버시, 심리적 상황 등에 따른 평가에 있어서는 불가능했던 단점을 동시에 가지고 있었다.

2) TESS와 TESS-NH의 과도기 단계에 만들어진 TESS-2+의 경우는, 8 개의 Protocols의 설정을 통해 더욱더 세밀한 항목 으로 구체화된 개발 매뉴얼로서, 입주자(치매성 고령자)의 시 설사용의 활동 반경을 넓게 설정한 특색을 알 수 있었다.

또한 시설의 유지·관리적 측면의 강조를 통해 입주자의 안 
전에 대한 지속적인 케어에 대한 평가를 하는 특징을 볼 수 있었다.

3) 최종 완결판 TESS-NH의 경우는, 총 13 개 Protocols의 설정을 하여 입주자의 안전, 프라이버시, 유지관리, 액서스, 조명, 잡음, 공간성 등의 케어의 질(Quality of Care)의 향상 을 위한 면밀한 평가항목을 구성하였다.

이것은 물리적 환경에 대한 평가 뿐 만이 아니라, 입주자 의 심리적 반응과 시설 및 기타 외부환경과의 접촉을 통한 상호작용에 이르기까지 포괄적 환경의 상태를 반영함으로 치 료적 효과를 이루게 하는 평가항목의 척도가 완성되었음을 알 수 있다.

4) 치매성 노인요양시설에 있어서 치료적 환경평가에 영향 을 주는 평가척도의 주요인을 확인하기 위해 TESS-NH 4개의 속성(Attributes)에 귀속되는 총12개의 프로트콜(Protocols)을 설문항목(Contents)화 하여 주성분분석(PCA)을 실시한 결과, 세 가지의 주요인을 밝힐 수 있었다. 먼저, 시설 관리에 대한 배려(Care for facilities' maintenance)의 경우, 요양시설 내부 의 시설관리 소홀이 원인이 되어 치매성 노인에게 시각, 촉 각, 자극과 관련한 물리적 장애를 초래할 수 있음으로 이에 대한 배려가 중요하다는 환경평가척도 주요인을 알 수 있었 다. 다음으로, 공간인지에 대한 배려(Care for spatial cognition)의 경우는, 치매성 노인의 대부분은 공간인지, 방향 감각 등의 능력이 현저히 저하됨으로 이에 대한 적극적인 배 려가 중요하다는 환경평가척도의 주요인을 알 수 있었다. 마 지막으로, 안전을 위한 배려(Care for safety)에서 치매노인은 동행자가 동반하지 않을 경우 안전, 신변상의 문제가 발생 소지가 크므로 홀로 다니기를 방지하기 위한 "출입구 통제" 등을 통한 안전유지 및 관련한 관리의 배려가 중요한 환경평 가척도의 주요인으로 작용한다는 것을 알 수 있었다.이 세 가지 요인들의 공통적 특징은, 요양시설 내부에 있어서 입주 자(치매성 고령자)가 보다 안전하고, 편안한 공간 및 시설물 의 사용에 대한 배려가 영향을 주고 있다는 의미로서, 향후 우리나라의 환경평가척도 개발단계에서 적극적으로 검토해야 할 사항이라고 볼 수 있다.

5) 본 연구 결과를 통해, 향후 우리나라에 급속히 보급되 는 치매성 노인요양시설에 있어서 개별적 케어에 대한 보급 의 정착과 함께, 케어의 질(Quality of Care)의 확보에 초점에 맞춰진 중요한 시설환경평가 가이드라인 구축의 계기가 되어 계획자 및 설계자에 있어서 중요한 지침서로서 그 역할을 하 리라 기대해 본다.

단, 본 연구는 미국에서 개발된 TESS-NH 평가항목을 중심 으로 진행하였으나, 해외의 다른 선진국에서 사용되고 있는 평가항목척도에 있어서도 검토 및 비교분석 할 필요가 있다.

또한, 치료적 환경평가에 영향을 주는 평가척도의 주요인 을 위한 앙케트조사에서는 관련업종 전문가를 대상으로 실시 하였으나. 향후 연구에서는 실제 요양시설의 담당자 및 보호 자 등과 같은 직접적으로 관련되는 피험자를 대상으로 조사
및 분석을 실시할 필요가 있다.

\section{References}

김태민 외, 2011, "노인 삶의 질 향상을 위한 노인요양시설 친환경 설계 기법에 관한 연구 -자연형 설계기법을 중심으로-", 한국인테리어디 자인학회지 제20권 제6호, pp.216-217

김한덕, 2013, "노인요양시설운영의 만족도에 영향을 미치는 요인", 한 국사회복지지원학회 제8권 제1호, pp.270-271

박진경 외, 2011, "노인요양시설의 유니버설 디자인 적용성 평가연구", 한국인테리어디자인학회지 제20권 제1호, pp.5-11

이연숙 외, 2011, "치매노인환경을 위한 선도적 디자인 지침의 체계 비 교 분석", 대한건축학회논문집 계획계 제11호(통권277호), pp.94-96 임채숙, 2011, "한국형 노인복지시설을 계획하기 위한 유니버설 공간·환 경디자인 지침 제안", 디자인학연구 제24권 제4호, pp.69-71

조주영 외, 2011, "물리적환경과 치유요소를 고려한 치매노인요양시설 치유환경 평가도구 연구", 대한건축학회종합논문집 제 13 권 제 1 호, pp.103-107

추연철 외, 2010, "노인요양시설의 이용특성 및 공간구성에 관한 연구", 한국농림건축학회논문집 제13권 제3호, pp.58-63

통계청, 고령자통계, 2011

Day K. Carreon D. and Stump C, 2000, "The Therapeutic Design of Environments for People with Dementia:Areview of the Empirical Research", The Gerontological Society of America, The Gelontologist, Vol.40, No.4, pp.397-416

Grant L.A., 1996, "Assessing environment in Alzheimer special care unit:The Nursing Unit Rating Scale," Research on Aging, 18, pp.275-291

JONAS E. ANDERSSON, 2011, "Touching up" Communal Space of a Residential Home Setting: A Comparative Study of Tools for Assessing Changes in the Interior Architectural Space", Journal of Housing For the Elderly, vol.25, pp. 175-216

Kovach C. Weiseman G.D. Chaudhury H. \& Calkins C. 1997, "Impacts of a therapeutic environment for dementia care," American Journal of Alzheimer's Disease, pp.99-110

Lawton M.P. Weiseman D.G. Sloane P. and Calkins M. 1997, "Assessing Environments for Older People with Chronic Illness, In Teresi M.P. et al (eds.) Measurement in Elderly Chronic Care Population",Springer Publishing Co., pp.193-209

Mooney, P., Nicell, P.L., 1992, "The importance of exterior environment for Alzheimer residents: Effective care and risk management",Healthcare Management Forum, University of British Columbia, Landscape Architecture Program, Vancouver, BC, Canada, Volume 5, Issue 2, pp.23-29

Philip D. Sloane. Sheryl Zimmerman, "Therapeutic Environment Screening Scale For Nursing Homes and Residential Care(TESS-NH/RC):MANUAL",Sheps Center for Health Services Research, University of North Carolina at Chapel Hill

Sloane, Philip DView, Mitchell, C Madeline, Weisman, Gerald, Zimmerman, SherylView, Foley, Kristie M Long, et al. 2002, "The Therapeutic Environment Screening Survey for Nursing Homes (TESS-NH): an observational instrument for assessing the physical environment of institutional settings for persons with dementia", The journals of gerontology. Series B, Psychological sciences and 
social sciences57.2, pp.69-78

Thomas, D.W., 2008, "Ukrainian inpatient dementia care: A case study of two neuropsychiatric hospitals", School of Health Sciences, Eastern Michigan University, Ypsilantim, MI, United States, Volume 7, Issue 2, pp.239-249

Weiseman G.D., "Creating Places for People with Dementia: An Acton Research Perspective in Schaie K. W. et al(eds.), Aging in the Community: Living Arrangements and Mobility,"Springer Publishing Co.,in press

Weiseman G.D. Lawton M.P. Calkin M. \& Norris-Baker L., 1996, "The Professional environmental assessment protocol", School of Architecture, University of Wisconsin at Milwaukee

접수 : 2014년 6월 30일 1차 심사 완료 : 2014년 7월 18일 게재확정일자 : 2014년 8월 8일 3 인 익명 심사 필 